\title{
SAUSSURE E A LINGUAGEM DO XADREZ NA CONSTRUÇÃO DAS PERSONAGENS EM "MINHA GENTE", DE JOÃO GUIMARÃES ROSA
}

\author{
Marilani Soares Vanalli ${ }^{1}$, Thamires Ferreira dos Santos ${ }^{2}$ \\ ${ }^{1}$ Universidade do Oeste Paulista - UNOESTE, Presidente Prudente, SP. Universidade Estadual Paulista - UNESP, \\ Doutorado em Literatura, Assis, SP. ${ }^{2}$ Especialização em Literatura e Jornalismo: Práticas Textuais, Presidente Prudente, \\ SP.E-mail: marilani@unoeste.br
}

\section{RESUMO}

Pretende-se com este artigo exemplificar a construção da imagem do homem campesino na literatura brasileira, e não só analisar o perfil dos personagens principais do conto "Minha Gente" de Guimarães Rosa - publicado em 1946 no livro Sagarana - como também da aplicação da teoria de Saussure que estabelece uma metáfora entre o jogo de xadrez e a linguagem. A metodologia constou de pesquisa bibliográfica, e far-se-á a leitura de tais características. O objetivo principal deste trabalho é que mostrando as personagens atuantes como peças de um jogo no conto, assumem uma condição de verossimilhança com relação à vida real. Nestas estratégias da enunciação do narrador, serão utilizados autores especialistas nesse referido jogo, como sustentação inicial, a teoria Saussuriana que estabelece parâmetros comparativos entre o funcionamento da língua e o jogo de xadrez, e também, teóricos como Bakhtin e Antonio Candido para definir aspectos da literatura em si.

Palavras-chave: personagens, Saussure, peças, xadrez, interpretação.

\section{SAUSSURE AND THE CHESS LANGUAGE IN THE CONSTRUCTION OF CHARACTERS IN "MINHA GENTE” (“MY FOLKS”), BY JOÃO GUIMARÃES ROSA}

\begin{abstract}
The aim of this article is to illustrate the construction of the image of the country man in Brazilian literature, and not only to analyze the profile of the main characters of the story "My People" by Guimarães Rosa - published in 1946 in the book Sagarana - as well as the application of Saussure's theory establishing a metaphor between the game of chess and language. The methodology consisted of bibliographic research, and such characteristics will be read. The main objective of this work is to show that the characters act like pieces of a game in the story, thus taking up a likelihood condition in relation to real life. In these enunciation strategies of the narrator, specialists will be mentioned in this so-called game, as initial support, the Saussurian theory establishing comparative parameters for the functioning of the language and the game of chess and theorists as Bakhtin and Antonio Candido as well to define aspects of literature itself.
\end{abstract}

Keywords: characters, Saussure, pieces, chess, interpretation. 


\section{INTRODUÇÃO}

Muitos textos trazem como temática central a vida campestre e os moradores deste espaço rural. Ao retratar a cultura pastoril, é possível perceber evidenciado em alguns textos, um olhar preconceituoso do homem urbano em relação ao do campo. Como observa Candido (2011, p. 175) "as diversas manifestações literárias trazem os valores preconizados pela sociedade, visto que, cada sociedade cria as suas obras ficcionais de acordo com os seus impulsos, as suas crenças, os seus sentimentos e as suas normas, a fim de fortalecer em cada um a presença e atuação deles". Posto isto, entende-se que a sociedade valoriza a imagem do homem urbano, aqueles que não se enquadram neste perfil, recebem um olhar de exclusão.

Com intuito de exemplificar a construção da imagem do homem campesino na literatura brasileira, este artigo não só analisará o perfil dos personagens principais do conto "Minha Gente" de Guimarães Rosa - publicado em 1946 no livro Sagarana - como também tratará da aplicação da teoria de Saussure que estabelece uma metáfora entre o jogo de xadrez e a linguagem.

Neste conto, Guimarães Rosa mostra traços de sua terra natal, sob a perspectiva de um narrador-personagem em situações que exemplificam um embate entre o campo e a cidade. Configura-se assim, uma obra polifônica definida por Bakhtin (apud Marcuzzo, 2008) como "aquela em que o autor se separa ou funde-se imperceptivelmente às vozes do texto, ou melhor, encontra sua voz ao orientar as vozes criadas por ele, e estas surgem de outas vozes, ou contrapondo-as".

A polifonia criada por Guimarães Rosa na construção desta pequena narrativa é confirmada pela possibilidade de se esmiuçar, neste estudo, algumas das múltiplas vozes construídas pelo autor, analisando-as como aquelas que proporcionam vários pontos de vista.

Contextualizando, a história escolhida para análise se passa na fazenda Saco-doSumidouro. O narrador, visita a família do seu tio no interior de Minas Gerais, e logo no primeiro parágrafo descreve o que já aprendeu.

Pode-se perceber no excerto em Sagarana (1978, p. 174):

Já sabia que das moitas de beira de estrada trafegam para a roupa da gente umas bolas de centenas de carrapatinhos [...]; que não valia a pena pedir e nem querer tomar beijos às primas; [...] que, quando um cavalo começa a parecer mais comprido, é que o arreio está saindo para trás [...] Mas muitas mais outras eu ainda tinha que aprender.

Durante o trajeto do herói até a fazenda, há a disputa de uma partida de xadrez entre ele e Santana; este é descrito como um apaixonado pelo esporte, já aquele o pratica esporadicamente. Os movimentos do xadrez permeiam toda história, criando uma metáfora velada da vida ao jogo, espaço narrativo em que as pessoas são vistas como as peças.

Rocha (2010, p. 15) referenda que:

Etimologicamente o termo metáfora tem origem na palavra grega metaphorá, palavra formada da união dos termos meta que significa "sobre" e pherin que significa "transporte", mais especificamente, estamos falando de um transporte de sentido. Esta figura de linguagem proporciona a expressão de ideias de uma maneira inovadora, liberta a palavra de seu sentido literal e permite novas interpretações da realidade.

Percebe-se que as metáforas são usadas como mecanismos demonstrativos de fenômenos ou processos abstratos. Uma história ou conto possui um sistema que orienta sua continuidade, como em um jogo. As personagens de uma história têm diferentes funções, no entanto o impacto delas no decorrer da narrativa, dependem do desempenho das outras, como em uma partida. Conforme o Doutor em Teoria Literária Ricardo Vigna (s.d) na teoria saussuriana, referencia que o 
jogo e a língua são organizados por convenções sociais, isto é, um pacto de que as palavras e as peças funcionarão de uma maneira normativa, pois as regras do jogo, a gramática e o léxico devem ser aceitos por quem queira jogar ou falar uma língua.

Quanto a teoria de Saussure - que estabelece uma metáfora entre o jogo de xadrez e o funcionamento da língua - este estudo, relacionará os diálogos das personagens do conto "Minha Gente" com a função das peças do jogo de tabuleiro, explicando como a história se desenvolve a partir de estratégias.

O objetivo desta pesquisa é de fazer uma breve interpretação da relação estabelecida por Guimarães Rosa entre a vida das personagens do conto "Minha Gente" em um jogo de xadrez e como se assemelham à vida real em sociedade.

\section{METODOLOGIA}

A linguagem é um sistema que só aceita sua própria ordem. A metáfora do jogo de xadrez é utilizada por Saussure filósofo da linguagem, em diversas passagens de suas teorias da língua enquanto sistema de signos, para explicar e o funcionamento de suas unidades constituintes.

Saussure (apud Rocha, 2010, p. 26) menciona que:

De todas as comparações que se poderiam imaginar, a mais demonstrativa é a que se estabeleceria entre o jogo da língua e uma partida de xadrez. De um lado e de outro, estamos em presença de um sistema de valores e assistimos às suas modificações. Uma partida de xadrez é como uma realização artificial daquilo que a língua nos apresenta sob forma natural.

Na língua, a relação entre uma palavra e outra permite aos interlocutores perceber o significado dos textos. No xadrez, cada partida é única, no entanto os nomes e as funções das peças não mudam.

Os "jogadores" compõem diferentes frases e textos, todavia o significado das palavras, as organizações sintáticas, etc., de certa forma, se conservam [...] Língua, portanto, é o sistema abstrato convencionado por um grupo social, regido por um código de funcionamento que lhe garante certa unidade e que surge em certas condições histórico-políticas. É ela o principal objeto da Linguística saussuriana.

Uma partida de xadrez permite metaforizar um diálogo entre diferentes locutores, por ser exercitado entre duas pessoas que tencionam algo, seja estabelecer um debate, seja persuadir o outro a executar determinada ação.

Segundo Moraes (2014, p.66):

o jogo de xadrez não objetiva capturar o maior número de peças do adversário, mas sim lançar mão de estratégias que cerquem o rei inimigo e eliminar suas rotas de fuga, o chamado xeque-mate. Um bom jogador, deve ser capaz de visualizar em sua mente várias jogadas à frente, encontrando a melhor forma tática a ser aplicada. Estratégia e decisão tomadas individualmente.

Valendo-se de levantamento bibliográfico, conclui-se que as personagens secundárias do conto "Minha Gente" podem ser classificados como bons enxadristas, ou como as peças mais fortes do tabuleiro, em virtude de anteciparem as atitudes do protagonista, induzirem constantemente seus movimentos, compelindo-o de tal modo que ele acaba impotente e encurralado. "O xadrez - também chamado de Arte de Caissa ${ }^{1}$ - requer, portanto, habilidade

\footnotetext{
${ }^{1}$ Arte de Caissa: é uma forma poética de referir-se ao jogo de xadrez. Apesar de Caissa ser um símbolo do xadrez, ela foi criada após o próprio jogo. Caissa é a musa de uma poesia escrita por Willian Jones em 1763. A ninfa do bosque pede que o deus da guerra Marte crie um jogo. Ele concebe o xadrez e o apresenta com o nome de Caissa. Este poema ganhou popularidade na França e também foi publicado na primeira revista de xadrez - La Palaméde - em Paris em 1836. (Braga, 2006 apud Moraes, 2014)
} 
(jogo), imaginação (arte) e cálculo (ciência). A prática, o estudo e o raciocínio são os fatores de progresso". (BECKER, 2002, p.9, grifo do autor). Como bons estrategistas, as figuras dramáticas satisfazem apenas às suas próprias vontades.

Ao considerar essa colocação, pensa-se com Candido (2006, p. 84), que "a obra não é produto fixo, unívoco ante qualquer público; nem este é passivo, homogêneo, registrando uniformemente o seu efeito". O que se pode refletir é que são vozes que se sobrepõem e atuam uma sobre a outra somadas também a do autor. Este estudo trará agora uma análise sucinta da atuação dos personagens do conto de Guimarães Rosa como xadrezistas.

\section{RESULTADOS}

Tomando por princípio o conceito de Antonio Candido (2006, p. 85) de que o público é o "mediador entre o autor e a obra, na medida em que o autor só adquire plena consciência da obra quando ela the é mostrada através da reação de terceiros", as obras são passíveis de livre interpretação. Logo, o primeiro personagem a ser interpretado a partir de suas características, relacionadas às peças de xadrez será o protagonista do conto.

Antes de tudo, vale ressaltar que o personagem principal não tem nome. "Um narrador autodiegético $^{2}$ [...] Não informa, em momento algum, seu nome, ocupação, filiação, nem se a visita ao tio ocorre durante um período de férias" (KIELING, 2012, p. 1). Este fator é crucial na concretização da figura deste homem da cidade que visitava o campo como uma peça no jogo político e o amoroso por parte dos familiares dele.

O herói do conto pode ser comparado a um Peão do tabuleiro de xadrez, porque, conforme Becker (2002, p. 97), "os Peões são a verdadeira base de toda a estratégia do xadrez, diante do seu Peão os grupos mais fortes ganham sempre". Ou seja, mesmo valendo-se da "vantagem" de ser um homem da cidade, o narrador acaba sucumbindo às vontades das pessoas da fazenda. Sendo assim, a propensão do narrador sofrer manipulações, está implícita no fato de este não ter nome.

Por isso, a partir da interação entre o protagonista e tio Emílio, e com Maria Irma será determinado seu perfil como Peão. Partindo de tio Emílio, observa-se que para o narrador ele foi "transformado e melhorado" no intervalo de seis anos entre suas visitas. O sobrinho tinha uma péssima figura do tio, recordava-se dele como um homem mole para tudo e desajeitado, agora Tio Emílio é outro: rejuvenescido, transfigurado, de andar e olhar confiantes. Ele estava envolvido na política.

Tio Emílio é um Peão transformado em Dama, conforme Lasker (1962, p. 76) "quando um Peão é promovido movimenta-se de modo não perpendicular ao eixo". Ou seja, as atitudes de tio Emílio tornaram-se semelhantes às de um Rainha, considerando-se que, segundo Moraes (2014, p. 59) "um simples peão pode decidir o final da partida ao transformar-se na poderosa dama". Mostra como é difícil para um homem pobre agir corretamente quando sobe de posição. Sua postura ilustra como a ambição corrompe o homem.

A temática política é percebida na reação do tio Emílio diante do assassinato de um empregado da fazenda. O morto era Bento Porfírio, homem casado, que mantinha um relacionamento com Lourdes, também casada. Xandão, o marido traído, mata Bento enquanto este pescava com o protagonista, como se percebe no fragmento de Sagarana $(1987$, p. 194) a seguir:

- Mas, Tio Emílio, o senhor que é tão justiceiro e correto, e que gostava tanto do Bento Porfírio, vai deixar isto assim? Não vai mandar, depressa, gente atrás do Alexandre, para ver se o prendem? Tio Emílio, alisando a sua palha, e com o sorriso que um sábio teria para uma criança, olhou-me, e

\footnotetext{
${ }^{2}$ O narrador autodiegético, proposto por Genette (1972), é aquele que narra a sua própria história ocupando a posição central da narrativa. Organiza o tempo e manipula a distância da narrativa. Este narrador viveu a história que conta, sabe detalhes aprofundados e pode contar tudo sobre a experiência vivida. Para este tipo de narrador é bastante comum a narração em primeira pessoa. Outras formas de narração são homodiegética e heterodiegética. (GENETTE, 1972, p. 98)
} 
disse: - Para os mortos... sepultura! Para os vivos... escapula!... Humilhei meus pendões. Calei-me. Meu tio esfregava nas palmas das mãos o fumo picado. Enrolou o cigarro. De súbito, bateu na testa e pulou: - Não é que eu não sei onde é que eu estava mesmo com a cabeça?! Ô Gervásio, corre aqui!... Já perdi um voto, e, se o desgraçado fugir para longe, são dois que eu perco...

O político se cala e cala também a opinião do protagonista de levar o caso à justiça, sustentando a imagem deste como Peão. O tio Emílio assume agora a posição de Rei no jogo, a julgar que para Lasker (1962, p. 166) "os movimentos e os poderes de captura do rei são em todas as direções porque a vontade do rei é lei". Ele não só enxerga a morte do empregado como apenas um entrave para a manutenção da força de sua corrente política, mas também como mais uma etapa do jogo/vida.

As referências ao jogo de xadrez continuam, com maior expressividade nos diálogos entre o protagonista e sua prima Maria Irma. O relacionamento deles fora um namoro de crianças, e o narrador diz-se apaixonado por ela. Os mecanismos de persuasão, o ato de entender como funciona a mente do outro, as relações entre os envolvidos fazem analogia à partida de xadrez.

É possível observar o trecho em que Maria Irma introduz no primo a ideia de que ele gostaria da noiva de Ramiro, (1987, p. 208)

- Então, para você, tanto faz que eu me interesse ou não por outra... Não é? - Ninguém manda em coração... - Me diz uma coisa, Maria Irma, você gosta um pouquinho de mim? - Por que não? Gosto de todos os meus parentes... E você nunca me fez mal nenhum... - Maria Irma! - Olha, os cavalos já estão arreados... Lá vem papai. E você não deve se atrasar... Vai gostar da Alda... Só que você gostaria mais de Armanda...

Pode-se perceber como Maria Irma joga com os sentimentos do primo/ Peão. Tanto que ao final da narrativa, o protagonista conhece Armanda por intermédio da prima, e eles se casam, assim como Ramiro e Maria Irma. Tomando-se por base o conceito apresentado, é possível confirmar o papel de Maria Irma como Rainha, uma vez que a Dama, segundo Moraes (2014, p. 63) "é a peça mais poderosa e fica ao lado do rei. Recebe uma ênfase muito grande no jogo devido a sua capacidade de movimentação".

As regras que dominam a movimentação das peças são como um ato manipulatório. Maria Irma configura o papel de Dama, sabendo que as Rainhas são tão cobiçosas que nada tomam a não ser por rapina ou injustiça, e suas ações são dissimuladas ou oblíquas.

\section{DISCUSSÃO}

Através de Maria Irma e tio Emílio, o narrador simula a cada circunstância uma nova jogada. Ante este fato é possível trazer a definição de Bakhtin (apud Marcuzzo, 2008, p. 8) acerca da voz do autor na construção das personagens:

O autor projeta o discurso em primeira pessoa, isto é, o sujeito da enunciação atribui a palavra e o saber a um narrador, mas ao mesmo tempo em que faz essa delegação, o sujeito da enunciação, por meio de outra ou de outras vozes, desqualifica o narrador como sujeito do saber, mais precisamente, do saber interpretar. Não há, dessa forma, no discurso, uma voz "confiável" que possa interpretar e resolver a ambiguidade narrativa. 
Curiosamente, Bakhtin discordava das concepções de Saussure relacionadas à linguagem, pois este entendia a língua como um sistema de formas, estável e imutável, abstraído das relações sociais, enquanto que para aquele a língua é constituída justamente nas relações sociais.

O que se busca relacionar é a metáfora saussuriana da formação da língua com um jogo de xadrez à construção das personagens a partir dessa mesma premissa. Valendo-se de que as características de antever os passos do outro são uma das principais características dos xadrezistas.

Ao se tomar o texto como uma metáfora entre o jogo e a vida, percebe-se que quem joga tem a ilusão de comandar as jogadas, assim como na realidade. A escolha das palavras, ou seja, o domínio da linguagem é como a Arte de Caissa, segundo Rocha (2010, p.18), "há uma ilusão de domínio na execução das jogadas, assim como há também uma impressão de domínio ao utilizar a língua. $O$ indivíduo pensa dominar a língua assim como o eu-lírico pensa dominar as jogadas de xadrez".

Viu-se que durante todo o conto "Minha Gente" o protagonista pensou dominar suas escolhas, quando na verdade os personagens secundários regiam suas ações. Da mesma forma, o autor pensa dominar a língua, quando na verdade as regras gramaticais e léxicas coordenam suas ações. No entanto, não limitam as possibilidades de criação.

Conclui-se assim que o andamento de uma história ou de um jogo não dependem exclusivamente de se compreender o posicionamento das peças, as regras e os limites de relacionamento entre as partes envolvidas. No caso dos textos, cabe ao autor estabelecer esses destinos, e acima de tudo cabe também a cada leitor ou jogador definir a força de cada uma das peças/ personagens.

\section{REFERÊNCIAS}

BECKER, Idel. Manual de xadrez: generalidades, aberturas, meio-jogo, finais, partidas (miniaturas, imortais", magistrais), problemas, miscelânea, curiosidades, o xadrez no Brasil; Apêndice. 320 p. São Paulo: Nobel, 2002.

CANDIDO, Antonio. Literatura e Sociedade. 9. ed. Rio de Janeiro: Ouro Sobre Azul, 2006. 199 p. cap. 4: 0 escritor e o público, p. 83-98. Disponível em: < http://www.fecra.edu.br/admin/arquivos/Antonio_Candido_-_Literatura_e_Sociedade.pdf>. Acesso em: 20 jul. 2016.

Vários Escritos. 5. ed. Rio de Janeiro: Ouro Sobre Azul, 2011. 272p. cap. 12: O direito à literatura, p. 169-191.

GENETTE, G. Discurso da narrativa - Figuras III. São Paulo: Veja, 1972.

KIELING, Márcia Schild. "Minha gente": o peão e o enxadrista. Letras de Hoje, Porto Alegre, v. 47, n. 2, p. 201-204, abr./jun. 2012. Disponível em: < http://revistaseletronicas.pucrs.br/fzva/ojs/index.php/fale/article/view/11317/7722>. Acesso em: 20 jul. 2016.

LASKER, Edward. A Aventura do Xadrez. São Paulo: Ibrasa, 1962.

MARCUZZO, Patrícia. Diálogo inconcluso: os conceitos de dialogismo e polifonia na obra de Mikhail Bakhtin. Cadernos do IL, Porto Alegre, n.o 36, jun. 2008. Disponível em: < http://www.seer.ufrgs.br/index.php/cadernosdoil/article/view/18908/11006>. Acesso em: 22 jul. 2016 
MORAES, Valéria Mastrogiuseppe. 0 xadrez pedagógico e o desenvolvimento do pensamento crítico. Americana: Centro Universitário Salesiano de São Paulo, 2014. 125f. Dissertação (Mestrado em Educação) - Centro Universitário Salesiano - UNISAL / SP.

ROCHA, Ina Mirely Oliveira da. Uma Partida de Xadrez com Saussure e Lacan: uma análise da relação entre sujeito e linguagem. João Pessoa: [s.n], 2010. 98f. :il. Dissertação (mestrado) - UFPb - CCHLA

ROSA, João Guimarães. Sagarana. 21.ed. Rio de Janeiro: J. Olympio ,1978. cap. 5: Minha Gente, p. 174-216.

VIGNA, Ricardo. Saussure - uma teoria da linguagem. [s.d]. Disponível em: < https://ricardovigna.wordpress.com/estudos-de-semiotica-e-filosofia-da-linguagem/1-1-aimportancia-da-linguagem/>. Acesso em: 20 jul. 2016. 